\title{
OPEN A bimolecular fluorescence complementation flow cytometry screen for membrane protein interactions
}

\author{
Florian Schmitz ${ }^{1,2}$, Jessica Glas ${ }^{1,2}$, Richard Neutze ${ }^{1}$ \& Kristina Hedfalk $^{1 \bowtie}$ \\ Interactions between membrane proteins within a cellular environment are crucial for all living \\ cells. Robust methods to screen and analyse membrane protein complexes are essential to shed \\ light on the molecular mechanism of membrane protein interactions. Most methods for detecting \\ protein:protein interactions (PPIs) have been developed to target the interactions of soluble proteins. \\ Bimolecular fluorescence complementation (BiFC) assays allow the formation of complexes involving \\ PPI partners to be visualized in vivo, irrespective of whether or not these interactions are between \\ soluble or membrane proteins. In this study, we report the development of a screening approach \\ which utilizes BiFC and applies flow cytometry to characterize membrane protein interaction partners \\ in the host Saccharomyces cerevisiae. These data allow constructive complexes to be discriminated \\ with statistical confidence from random interactions and potentially allows an efficient screen for PPIs \\ in vivo within a high-throughput setup.
}

To understand cellular networks that underpin normal cell function requires the robust identification of protein-protein interactions (PPI). PPIs participate in critical functions such as signalling, posttranslational modification, trafficking and environmental communication. When functional interactions are disrupted, this can lead to autoimmune diseases and cancer ${ }^{1}$. Membrane proteins and their PPI networks are common drug targets ${ }^{2}$, which adds emphasis to the need for better characterization of their PPIs. Aquaporins are a sub-family of integral membrane proteins that facilitate the passive transport of water across a biological membrane while preserving a transmembrane proton gradient. Aquaporin malfunction can lead to the development of a wide range of medical conditions including neurological disorders ${ }^{3-5}$, auto-immune diseases ${ }^{6}$ and inflammatory related responses ${ }^{7,8}$. Importantly, to explore the involvement of aquaporins in diseases, the understanding their regulatory processes by PPIs is crucial. A recent example is the interaction between aquaporin 4 (Aqp4), a human aquaporin mainly expressed in astrocytes, and calmodulin $(\mathrm{CaM})$ which has been shown to mediate re-localization of Aqp4 to the cell surface leading to cytotoxic edema, a condition of uncontrolled water influx that commonly occurs after injury ${ }^{9,10}$.

Several methods have been developed to detect PPIs, all of which are based upon different consequences of these interactions ${ }^{11}$. These techniques include Surface Plasmon Resonance ${ }^{12}$, Two-Hybrid methods ${ }^{13}$, and biochemical approaches such as Co-Immunoprecipitation ${ }^{14}$ and Pull-down assays ${ }^{15}$. Irrespective of whether or not the detection method is based upon biophysical, genetic or biochemical foundations, it is always necessary to assess whether the potential benefits of a given approach outweigh the method's inherent disadvantages. More recently, a variety of methods for surveying the interactome have emerged ${ }^{11,16}$, of which fluorescence-based techniques such as fluorescence resonance energy transfer (FRET) and Bimolecular fluorescence complementation (BiFC) for screening of PPIs in living cells ${ }^{17,18}$ have attracted attention. BiFC can be readily performed in different host systems ranging from plant cells ${ }^{19}$ to more complex mammalian cells like HEK $293^{20}$. Complementation fluorescence was initially quantified using fluorescence microscopy ${ }^{21}$. However, the benefits with flow cytometry for the analysis of fluorescence intensity became apparent enabling high throughput screening while avoiding artefacts arising from manual readout ${ }^{22}$. The detection of PPIs using BiFC pairing has intrinsic challenges such as unspecific fluorescence background signal due to self-assembly of the fluorophore partner, and possible tethering of BiFC partners during translation and translocation ${ }^{23}$. Thus, while BiFC is a highly attractive option, when using BiFC it is essential to keep awareness of these limitations ${ }^{24}$.

\footnotetext{
${ }^{1}$ Department of Chemistry and Molecular Biology, Gothenburg University, Box 462, 40530 Göteborg, Sweden.

${ }^{2}$ These authors contributed equally: Florian Schmitz and Jessica Glas. ${ }^{\varpi}$ email: kristina.hedfalk@gu.se
} 
Day 1

Day 2

Day 2-5

Day 6

Day 7

Day 8
S.cerevisiae $\mathrm{O} / \mathrm{N}$ in $10 \mathrm{~mL}$ YPD, $30^{\circ} \mathrm{C}$, shaking

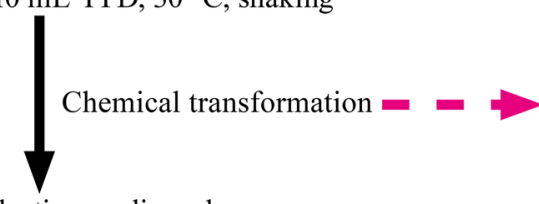

Plate on selective media and incubate at $30^{\circ} \mathrm{C}$

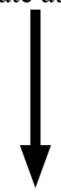

Masterplate: 20 colonies per construct

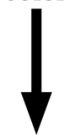

Innoculate $5 \mathrm{~mL}$ selective media and incubation at $30^{\circ} \mathrm{C}$ and shaking

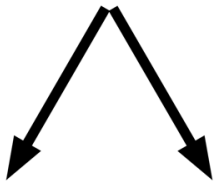

Expression verification

Interaction verification

Confocal microscopy

Western Blot

FACS measurements
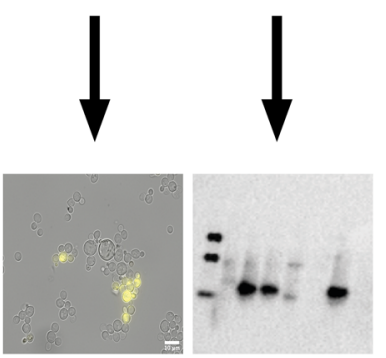

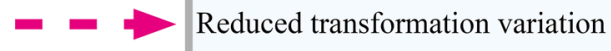

Critical requierements

Freshly prepared chemicals PEG and LiAc

Efficiency control

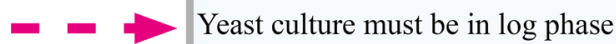

Figure 1. Experimental design of a standardized cell preparation for expression and interaction analysis of BiFC complexes produced in Saccharomyces cerevisiae cells. The schedule shows that the whole screening process is completed in less than 14 days, emphasizing critical steps.

In a previous study we established the BiFC method to validate the direct PPIs between the tetrameric complex formed by human aquaporin 0 (hAQP0) alone, and with the regulatory protein Calmodulin (CaM). Each protein target was attached to a complementary YFP molecule and both yielded BiFC complexes when expressed within the yeast host Saccharomyces cerevisiae ${ }^{25}$. This process was driven by the specific interaction between aquaporin molecules, or between CaM and the C-terminus of $\mathrm{hAQP0}{ }^{26}$ which brought the YFP fragments into close proximity. The maturation of YFP was followed by the fluorescence read-out, providing a method for membrane protein complex screening whereby the in vivo interaction can be analysed directly within the expression host membrane. The formation of PPI complexes was independently confirmed by Native Page ${ }^{25}$. Here we further develop this screening procedure by applying population screening and quantification of the BiFC complex using flow cytometry, thereby establishing a complete procedure from the transformation and growth of cells to the analysis of the fluorescent signal. This protocol facilitates a higher throughput relative to traditional, labour intensive approaches and could be utilized to screen for novel PPIs.

\section{Results}

Expression of aquaporin BiFC constructs in S. cerevisiae. We analysed the expression and interactions of Aqp0 using the experimental design summarized in Fig. 1. All samples show an intrinsic variation in the fluorescence of the transformants when measured using flow cytometry. To minimize this effect, fluorescence cytometry was used as a pre-check on ten samples taken directly from the growth plate to evaluate the transformation efficiency. If fluorescence was detected from these colonies, the transformation was considered successful and twenty colonies were then picked and transferred to a fresh synthetic complete (SC) media agar plate. 

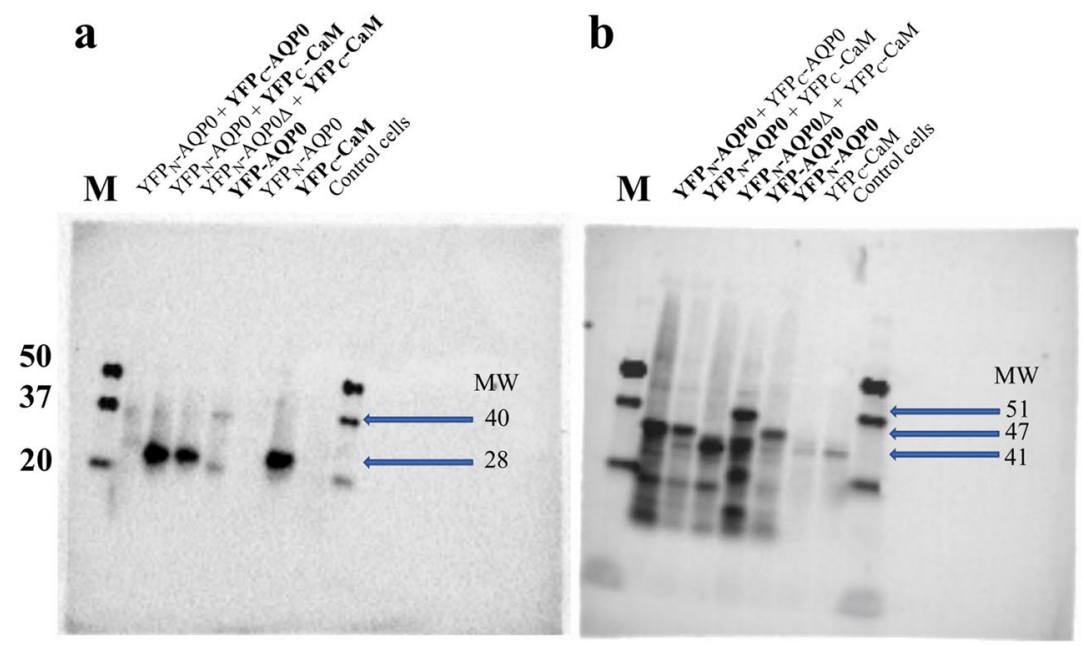

\section{BiFC fragment estimated mw}

$\begin{array}{ll}\text { YFP }_{\mathrm{C}}-\mathrm{AQP0} & 40 \mathrm{kDa} \\ \text { YFP }_{\mathrm{C}}-\mathrm{CaM} & 28 \mathrm{kDa} \\ \text { YFP }_{\mathrm{N}}-\mathrm{AQP0} & 47 \mathrm{kDa} \\ \text { YFP }_{\mathrm{N}}-\mathrm{AQP0} \Delta & 41 \mathrm{kDa} \\ \text { YFP-AQP0 } & 55 \mathrm{kDa}\end{array}$

Figure 2. Immunoblot analysis of the various BiFC complexes obtained from cell lysates. Samples were applied in the following order on the blots ( $\mathrm{a}$ and $\mathrm{b})$ : $(\mathrm{M})$ Marker, molecular weight in $\mathrm{kDa},(1)$ $\mathrm{YFP}_{\mathrm{N}}-\mathrm{AQP} 0+\mathrm{YFP}_{\mathrm{C}}-\mathrm{AQP0},(2) \mathrm{YFP}_{\mathrm{N}}-\mathrm{AQP0}+\mathrm{YFP}_{\mathrm{C}}-\mathrm{CaM}$, (3) $\mathrm{YFP}_{\mathrm{N}}-\mathrm{AQP} 0 \Delta+\mathrm{YFP}_{\mathrm{C}}-\mathrm{CaM},(4)$ $\mathrm{YFP}-\mathrm{AQP} 0$, (5) $\mathrm{YFP}_{\mathrm{N}}-\mathrm{AQP0},(6) \mathrm{YFP}_{\mathrm{C}}-\mathrm{CaM},(7)$ non-transformed $S$. cerevisiae cells. Monoclonal antibodies against $\mathrm{YFP}_{\mathrm{C}}(\mathrm{a})$ or $\mathrm{YFP}_{\mathrm{N}}$ (b) were used. The immunoblot confirms similar expression levels of the BiFC components. The bands corresponding to the BiFC fragments are indicated by arrows with the expected molecular weight and the part of the BiFC complex detected by the antibody is highlighted in bold.

This procedure was performed for a minimum of three biological replicates. Ten colonies from each transformation were then grown in liquid media to their log phase and analysed using flow cytometry. As negative controls, transformants containing only one plasmid of the BiFC pair were treated the same way.

To confirm proper production of individual entities of the BiFC-pair, standardized high density cell lysates of overnight cultures were separated by SDS-PAGE and analysed by immunoblot using anti-YFP split variant $\left(\mathrm{YFP}_{\mathrm{C}}\right.$, $\mathrm{YFP}_{\mathrm{N}}$ ) antibodies (Fig. 2). Although evidence for BiFC complexes could also be detected using this analysis, the major immunoblot signals correspond to individual parts and show an excess of expressed fragments relative to the BiFC complexes. Thus, immunoblot analysis verifies the production of all of the BiFC components when expressed within the host, and provides evidence that a small fraction of the expressed protein successfully forms mature BiFC complexes.

Mature BiFC complexes visualized by fluorescence microscopy. Intracellular production of mature BiFC complexes and the absence of fluorescent aggregates was confirmed using fluorescence microscopy. As was previously observed ${ }^{25}$ the most intense fluorescence signal was detected from the single plasmid transformant $\mathrm{YFP}-\mathrm{AQP0}$ (Fig. 3). By comparison, BiFC complexes requiring co-transformation $\left(\mathrm{YFP}_{\mathrm{N}}-\mathrm{AQP0}+\mathrm{YFP}_{\mathrm{C}}-\mathrm{AQP0}\right.$ and $\left.\mathrm{YFP}_{\mathrm{N}}-\mathrm{AQP0}+\mathrm{YFP}_{\mathrm{C}}-\mathrm{CaM}\right)$ yielded lower fluorescence intensities, which is highly intuitive since those constructs required that a complex formed between the co-expressed proteins and physical contact between both YFP fragments. Both the single plasmid control $\left(\mathrm{YFP}_{\mathrm{N}}-\mathrm{AQP} 0\right)$ and the C-terminus deficient BiFC complex formation control $\left(\mathrm{YFP}_{\mathrm{N}}-\mathrm{AQP} 0 \Delta+\mathrm{YFP}_{\mathrm{C}}-\mathrm{CaM}\right)$ showed extremely low fluorescence intensities, supporting the hypothesis that fluorescent YFP will not form if the CaM binding site of AQP0 is deleted. In addition to qualitative confirmation of fluorescence yields, brightfield fluorescence microscopy also provides information concerning the overall fitness of yeast cells since abnormal cell shapes may indicate stress.

Harvesting cells during log phase growth aids cytometry analysis. When analysing the formation of BiFC complexes by flow cytometry, a gate is required that selects individual intact yeast cells. Figure $4 \mathrm{a}$ provides an example of this procedure using the Aqp0-CaM BiFC complex formed when $\mathrm{YFP}_{\mathrm{N}}-\mathrm{AQP} 0$ and $\mathrm{YFP}_{\mathrm{C}}-\mathrm{CAM}$ come together in the cell. The selected domain is indicated within a sloping ellipse and $60.8 \%$ of all events were recorded within this gate. This analysis also revealed that a higher fraction of cells containing a mature BiFC complex formed when pre-selected fluorescent cultures are grown to the log-phase $\left(\mathrm{OD}_{600}=0.5\right)$ rather than when picking yeast cells directly from the SC agar plate. Specifically, the fraction of recorded events achieving a fluorescence yield above 500 fluorescence intensity units, which is the threshold to distinguish auto fluorescence from the YFP signal, was approximately four times higher for the Aqp0-CaM complex grown in liquid cultures rather than on plates $(21.4 \%$ versus $4.8 \%$, Fig. $4 \mathrm{~b})$. We therefore conclude that cultivating transformed cells in liquid cultures and harvesting these during their log phase aids the quantification of the cytometry fluorescent cells lines. This procedure was used throughout the remaining analysis.

Quantification of BiFC yields using flow cytometry. With conditions established for robust flow cytometry studies, we analysed the intensity and frequency at which a specific number of fluorescence counts occurred within a certain range of events for each of four constructs: YFP - AQP0; $\mathrm{YFP}_{\mathrm{N}}-\mathrm{AQP0}+\mathrm{YFP}_{\mathrm{C}}-\mathrm{AQP0}$; 


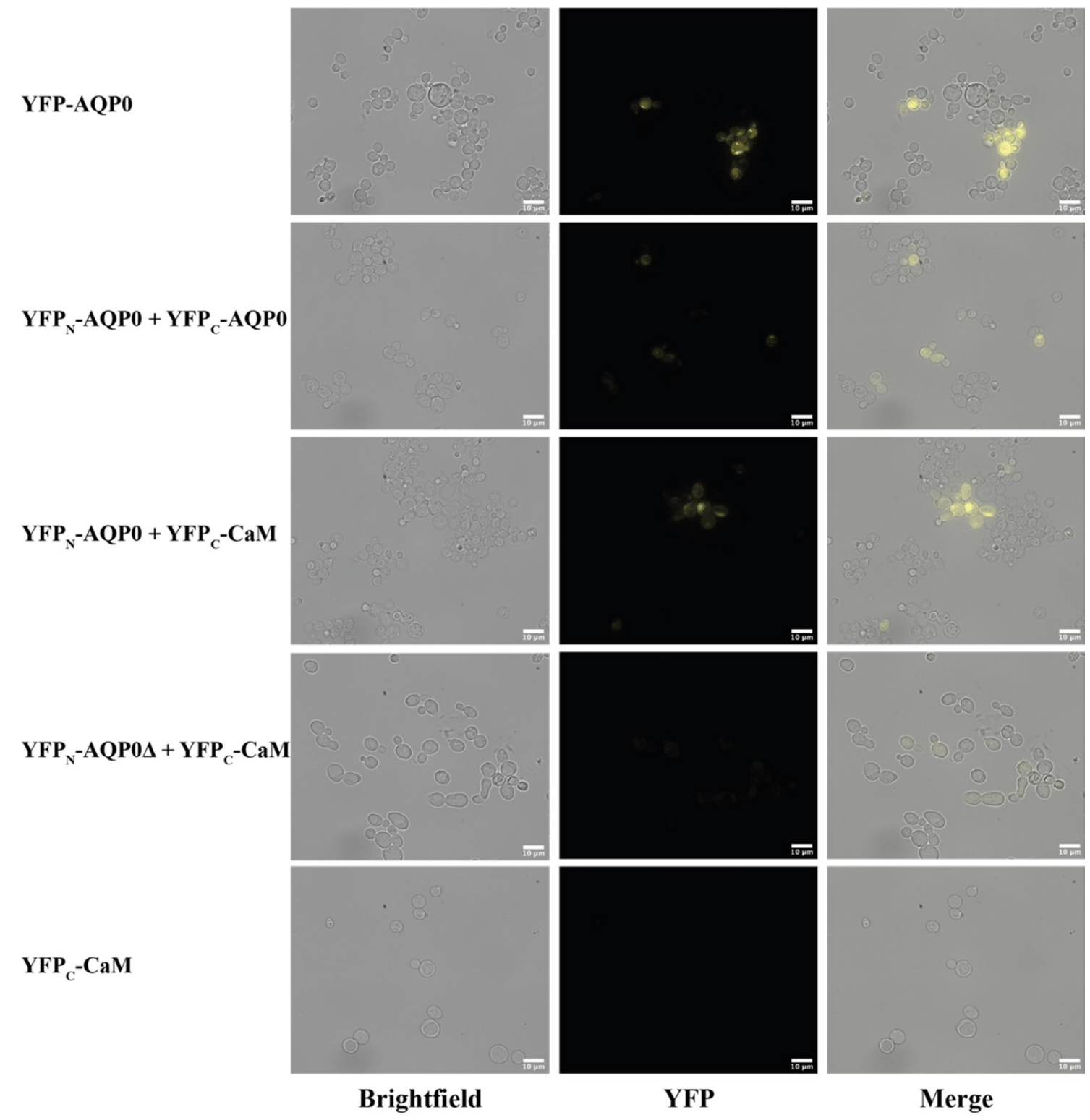

Figure 3. Bright field and fluorescence images of subcellular localisation of BiFC complexes produced in $S$. cerevisiae cells. Highest fluorescence signal was obtained from the positive control, cells producing the full length chromophore fused to human aquaporin 0, YFP - AQP0. Cells transformed with interaction complexes $\mathrm{YFP}_{\mathrm{N}}-\mathrm{AQP0}+\mathrm{YFP}_{\mathrm{C}}-\mathrm{AQP0}$ and $\mathrm{YFP}_{\mathrm{N}}-\mathrm{AQP} 0+\mathrm{YFP}_{\mathrm{C}}-\mathrm{CaM}$, respectively, showed an intermediate signal, while very faint fluorescence was observed for the $\mathrm{C}$-terminus deficient BiFC formation control, $\mathrm{YFP}_{\mathrm{N}}-\mathrm{AQP0} \Delta+\mathrm{YFP}_{\mathrm{C}}-\mathrm{CaM}$. Cells expressing single plasmid were used as non-fluorescent controls.

$\mathrm{YFP}_{\mathrm{N}}-\mathrm{AQP0} \Delta+\mathrm{YFP}_{\mathrm{C}}-\mathrm{CaM}$; and $\mathrm{YFP}_{\mathrm{C}}-\mathrm{CaM}$, where $\mathrm{AQP} 0 \Delta$ has the C-terminus removed (Table 1). The distribution of fluorescence intensity from the different constructs is illustrated by a histogram example for each construct, where the first peak is showing the auto fluorescence of all cells below the threshold value (500 fluorescence intensity units) and the second peak shows the distribution of all cells above the threshold value (Fig. 5a). Of those events which showed fluorescence, the intensity of this fluorescence signal was strongest for the positive control YFP $-\mathrm{AQP0}$ at $5600 \pm 700$ fluorescence units (Fig. 5b). This is indicated by the peak of the distribution being shifted to higher count-rates relative to those recorded for other samples (Fig. 5a) which is highly intuitive since this was the only construct to contain the full-length YFP, whereas all other constructs required two YFP fragments to be brought into close proximity prior to YFP maturation. In comparison, the second peak of $\mathrm{YFP}_{\mathrm{N}}-\mathrm{AQP0}+\mathrm{YFP}_{\mathrm{C}}-\mathrm{AQP0}$ and $\mathrm{YFP}_{\mathrm{N}}-\mathrm{AQP0}+\mathrm{YFP}_{\mathrm{C}}-\mathrm{CaM}$ is located further to the left where the peak of $\mathrm{YFP}_{\mathrm{N}}-\mathrm{AQP} 0+\mathrm{YFP}_{\mathrm{C}}-\mathrm{AQP0}$ is showing a clearer separation from the auto fluorescence peak than $\mathrm{YFP}_{\mathrm{N}}-\mathrm{AQP0}+\mathrm{YFP}_{\mathrm{C}}-\mathrm{CaM}$ visualizing as stronger distribution of cells with a higher average fluorescence intensity signal. Very few cells of the $\mathrm{YFP}_{\mathrm{N}}-\mathrm{AQP} 0 \Delta+\mathrm{YFP}_{\mathrm{C}}-\mathrm{CaM}$ complex display a fluorescence signal above auto fluorescence, resulting in a flat peak in comparison to the constructive BiFC complexes. However, the width 

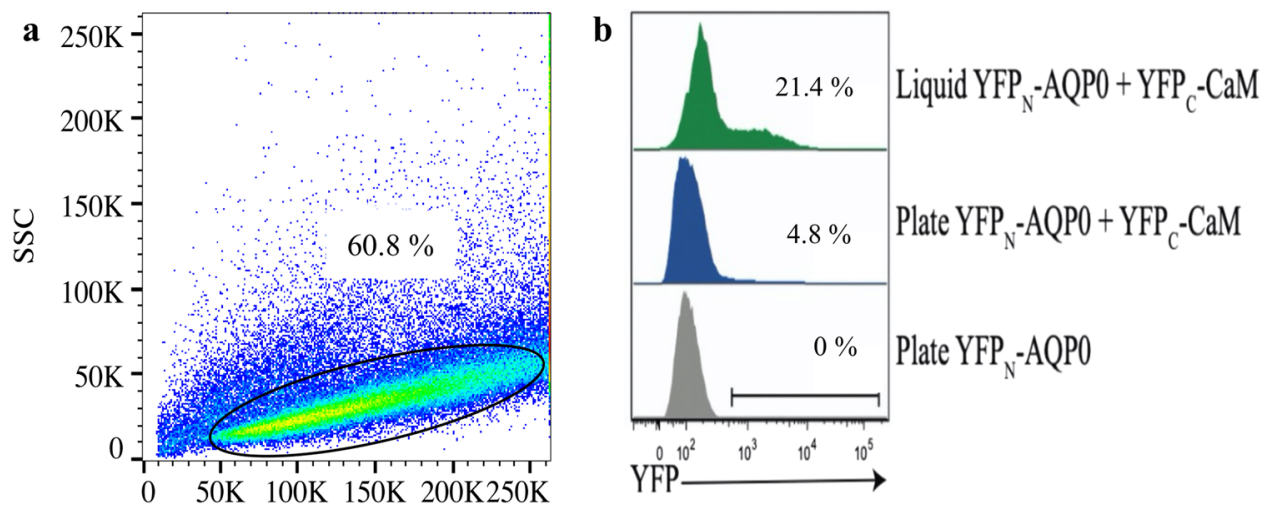

FSC

Figure 4. Flow cytometry quantification of BiFC yields. (a) An exemplary pseudo-color plot of Aqp0-CaM complex illustrating 100.000 events. A standardized gate, visualized as a sloping ellipse, selects individual yeast cells for analysis. $60.8 \%$ of all events were recorded within the selected domain. Side scatter (SSC on the y-axes is an indicator of complexity and forward scatter (FSC) on the x-axes is an indicator of size. (b) Comparison of the Aqp0 - CaM complex grown in SC liquid culture $\left(\mathrm{OD}_{600}=0.5\right)$ with the one grown on SC media plates. The fluorescence signal was evaluated from a threshold value of 500 intensity units.

\begin{tabular}{|l|l|l|l|}
\hline Constructs & Biological repeats & Technical repeats & Range of analysed events \\
\hline $\mathrm{YFP}-\mathrm{AQP} 0$ & 3 & $31(10+11+10)$ & $29,000-68,000$ (average 53,000$)$ \\
\hline $\mathrm{YFP}_{\mathrm{N}}-\mathrm{AQP0}+\mathrm{YFP}_{\mathrm{C}}-\mathrm{AQP} 0$ & 3 & $32(10+11+11)$ & $17,500-67,000$ (average 36,500) \\
\hline $\mathrm{YFP}_{\mathrm{N}}-\mathrm{AQP} 0+\mathrm{YFP}_{\mathrm{C}}-\mathrm{CaM}$ & 3 & $33(11+12+10)$ & $16,500-82,000$ (average 44,500$)$ \\
\hline $\mathrm{YFP}_{\mathrm{N}}-\mathrm{AQP0} \Delta+\mathrm{YFP}_{\mathrm{C}}-\mathrm{CaM}$ & 3 & $44(13+19+12)$ & $15,500-82,000$ (average 40,000$)$ \\
\hline $\mathrm{YFP}_{\mathrm{C}}-\mathrm{CaM}$ & 3 & $30(10+10+10)$ & $71,000-78,000$ (average 75,000$)$ \\
\hline
\end{tabular}

Table 1. Experimental setup for the evaluation of fluorescence intensity and relative YFP frequency of BiFC complexes. Number of biological repeats (independent transformation event) and technical repeats are shown for each construct. The range and average of events analyzed in each measurement are displayed.

of the peak indicates that the rare YFP maturation event leads to a similar fluorescence signal, which can be confirmed by Fig. $5 b$.

The fraction of events yielding more than 500 fluorescence counts per event were then calculated from these data. Both positive controls, YFP - AQP0 and $\mathrm{YFP}_{\mathrm{N}}-\mathrm{AQP} 0+\mathrm{YFP}_{\mathrm{C}}-\mathrm{AQP} 0$, gave sizeable populations of $21 \% \pm 5 \%$ and $17 \% \pm 5 \%$ respectively of cells displaying a fluorescence above this threshold. S. cerevisiae cells expressing both $\mathrm{YFP}_{\mathrm{N}}-\mathrm{AQP0}+\mathrm{YFP}_{\mathrm{C}}-\mathrm{CaM}$ constructs also showed fluorescence above 500 counts per event in $15 \% \pm 4 \%$ of the selected cells, slightly lower than that for the $\mathrm{YFP}_{\mathrm{N}}-\mathrm{AQP} 0+\mathrm{YFP}_{\mathrm{C}}-\mathrm{AQP} 0$ control. By contrast, the $\mathrm{YFP}_{\mathrm{N}}-\mathrm{AQP} 0 \Delta+\mathrm{YFP}_{\mathrm{C}}-\mathrm{CaM}$ constructs gave a much lower yield of $4 \% \pm 4 \%$ for the fraction of events to show fluorescence above this threshold (Fig. $5 \mathrm{c})$. The remaining single plasmid transformants $\left(\mathrm{YFP}_{\mathrm{C}}-\mathrm{CaM}\right.$ and $\mathrm{YFP}_{\mathrm{N}}-\mathrm{AQP0}$ ) which were included in the flow cytometry evaluation as negative controls, did not yield a significant fraction of events $(<0.1 \%)$ with fluorescence above threshold.

In summary, both constructive BiFC pairs show similar average fluorescence intensities, with the $\mathrm{YFP}_{\mathrm{N}}-\mathrm{AQP} 0+\mathrm{YFP}_{\mathrm{C}}-\mathrm{AQP} 0$ recording an average fluorescence intensities per event above threshold of $2200 \pm 700$ fluorescence units and the corresponding value for $\mathrm{YFP}_{\mathrm{N}}-\mathrm{AQP} 0+\mathrm{YFP}_{\mathrm{C}^{-}}-\mathrm{CaM}$ being $1500 \pm 200$ fluorescence units (Fig. 5b). Likewise, the $\mathrm{YFP}_{\mathrm{N}}-\mathrm{AQP} 0 \Delta+\mathrm{YFP}_{\mathrm{C}}-\mathrm{CaM}$ construct yields a similar value of $1500 \pm 100$ fluorescence units suggesting that these complexes, while relatively rare, fluoresce as much as a constructive BiFC complex but with a substantially higher variation. The control single plasmid transformants $\mathrm{YFP}_{\mathrm{C}}-\mathrm{CaM}$, on the other hand, did not show any analysable fluorescence fraction of events. Thus, similar fluorescence intensity of the constructive BiFC complexes $\mathrm{YFP}_{\mathrm{N}}-\mathrm{AQP0}+\mathrm{YFP}_{\mathrm{C}}-\mathrm{AQP} 0, \mathrm{YFP}_{\mathrm{N}}-\mathrm{AQP0}+\mathrm{YFP}_{\mathrm{C}}-\mathrm{CaM}$ and the construct $\mathrm{YFP}_{\mathrm{N}}-\mathrm{AQP0} \Delta+\mathrm{YFP}_{\mathrm{C}}-\mathrm{CaM}$ suggests that any complementation of the YFP molecule event results in a similar strong fluorescence signal. However, these events occur much less frequently in proteins that do not interact, and as a consequence the fluorescence frequency value has been shown to be the more accurate evaluation for detecting true interactions. 
A

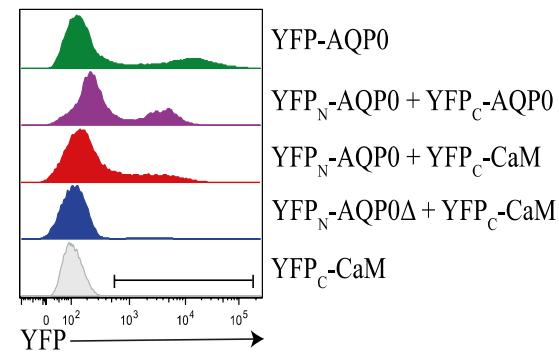

B

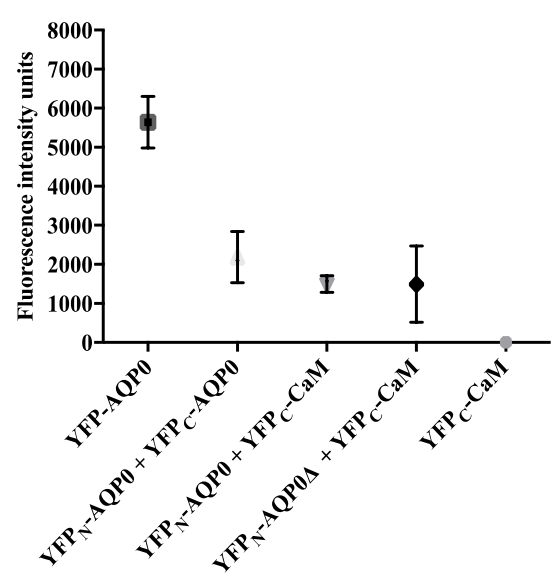

C

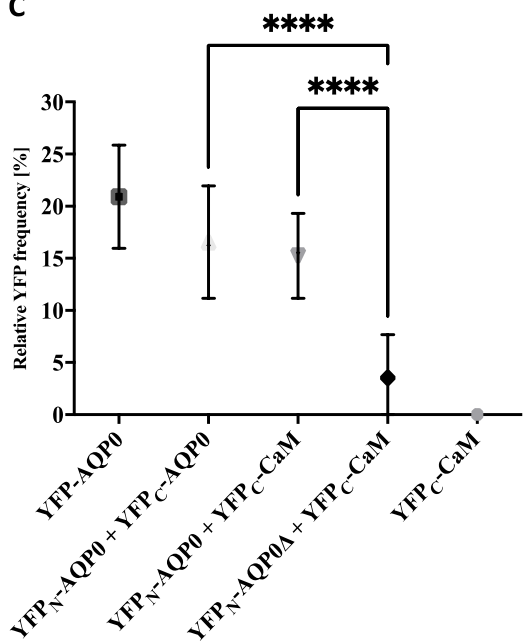

Figure 5. Quantification of BiFC yields using flow cytometry. (A) Analysis of constructs compared in this study together with the single plasmid negative control $\left(\mathrm{YFP}_{\mathrm{C}}-\mathrm{CaM}\right)$. The histograms show the distribution of fluorescence intensities in the log phase of growth. The fluorescence signal was evaluated from a threshold value of 500 intensity units, discriminating the YFP-signal from auto fluorescence. (B) Average fluorescence intensity is shown for each complex together with the standard error of the mean ( $\mathrm{n} \geq 10$ technical repeats based on at least three biological repeats, i.e. independent transformation events, see Table 1). (C) The average of the fraction of fluorescent cells in percentage is shown for each complex together with standard error of the mean $(n \geq 10$ technical repeats based on at least three biological repeats, i.e. independent transformation events). An unpaired two component t-test with Welch's correction was used to determine statistical difference of fluorescence frequency between $\mathrm{YFP}_{\mathrm{N}}-\mathrm{AQP0}+\mathrm{YFP}_{\mathrm{C}}-\mathrm{CaM}$ and $\mathrm{YFP}_{\mathrm{N}}-\mathrm{AQP} 0 \Delta+\mathrm{YFP}_{\mathrm{C}}-\mathrm{CaM}$ as well as $\mathrm{YFP}_{\mathrm{N}}-\mathrm{AQP0}+\mathrm{YFP}_{\mathrm{C}}-\mathrm{AQP0}$ and $\mathrm{YFP}_{\mathrm{N}}-\mathrm{AQP} 0 \Delta+\mathrm{YFP}_{\mathrm{C}}-\mathrm{CaM}$ with $p$ values $<0.0001$ demonstrating a statistically robust discrimination above a certain yield, as indicated ${ }^{* * *}$.

\section{Discussion}

Diverse host systems have been developed to support BiFC studies in prokaryotic cells ${ }^{27}$ eukaryotic yeast systems ${ }^{28-30}$ and human cell lines ${ }^{31}$. BiFC has previously been used to detect human aquaporin interaction partner in vivo ${ }^{25,27}$ and to confirm aquaporin PPIs in living plant cells $\mathrm{s}^{32,33}$. We previously developed a method for identifying PPIs by laboriously examining hundreds of fluorescence microscopy images ${ }^{25}$. The integration of flow cytometry readout for BiFC studies provides a step towards higher throughput screening of molecular PPI processes, both in human cells ${ }^{34}$ as well as in yeast cells ${ }^{29,30}$.

In this work we show how flow cytometry can reliably identify a validated PPI of an integral membrane protein when both proteins are expressed in S. cerevisiae. This development removes a subjective and timeconsuming step of a skilled researcher examining hundreds of images by eye and therefore has the potential to both achieve considerably higher throughput and to provide more quantitative foundations for the method. While BiFC complementation is an established method for the detection and validation of PPIs, it has intrinsic disadvantages of it being challenging to distinguish between background signal and valid molecular interactions leading to potential false-positives. The development of split fluorophores has improved signal-to-noise ratios $^{35}$, although it is common to report only the fluorescence intensities of complementation events. In this work we rationalized growth conditions prior flow cytometry measurements and this reduced unspecific BiFC background, providing a robust protocol that may allow unknown PPI interactions to be detected in a medium throughput manner (Table 1). Moreover, flow-cytometry analysis itself leads to quantification and statistically robust criteria emerge for identifying PPIs above background, with the proportion of cells displaying fluorescence events above threshold being, in this case, a more powerful criteria discriminating PPIs from false positives. In comparison to other studies, where the interaction between aquaporin isoforms and CaM has been verified by Microscale Thermophoresis (MST) ${ }^{9,26}$, BiFC complementation has the advantage of enabling quantification and screening of interactions in vivo and does not require prior purification of the proteins, which can be especially challenging for membrane proteins.

Furthermore, worth considering is that the distance and mutual orientation of the complexes can have a critical impact on the constructive BiFC pair formation. Therefore, it is important to test different combinations of construct design to find the optimal pair, as the way the fluorophore fragment and the protein of interest are combined plays a role in the efficiency of complex formation ${ }^{25}$. In addition, the correct construct design is also influenced by the choice of the flexible linker sequence between the YFP fragment and the protein of interest, as the linker length and the specific sequence have an influence on the expression, activity and localization of expressed proteins and their complexes ${ }^{36,37}$. In a further study, we have compared the YFP signal using two different linkers for the constructive $\mathrm{BiFC}$ complex $\mathrm{YFP}_{\mathrm{N}}-\mathrm{AQP} 0+\mathrm{YFP}_{\mathrm{C}}-\mathrm{CaM}$. Interestingly, using the longer linker, we obtained an enhancement in the YFP frequency signal but not in YFP intensity from the flow cytometry analysis (Supplementary Fig. 1). The length of the linker therefore also seems to have an influence on how likely it is that the YFP fragments mature into a complex. Another critical aspect for the construct design in the 
BiFC-evaluation is the inclusion of proper negative controls, where the most valid control is a non-constructive complex of the specific pair based on mutated proteins hindering the interaction ${ }^{38}$.

While the flow cytometry analysis demonstrated here satisfactorily identified fluorescent complexes, fluorescence imaging is a valuable complement in order to assure healthy cells are included in the analysis, and we recommend that the quality of the cells is checked for each designed construct. In particular, when using BiFC to study membrane protein complexes, the membrane localization of the complex can be confirmed and constructs leading to internal protein aggregates rejected. Moreover, some mutations that may be included as control studies can be complementary at the molecular level but may impact the overall health of the cells, yet this potential problem should be easily identified using confocal fluorescence microscopy.

In conclusion, we present an approach that combines qualitative and quantitative criteria for the screening of PPIs by combining BiFC, fluorescence imaging and flow cytometry. The relative frequency of cells showing fluorescence above a specified threshold is able to identify constructive complex formation with high statistical confidence (Fig. 5) while reducing the risk of false positives during screening for novel PPIs. We suggest that this approach could be further developed to allow high-throughput cDNA library screening of novel interaction PPIs ${ }^{39}$ by the use of fluorescence activated cell sorting (FACs) to sort out individual, promising candidates on the basis of their fluorescence and thus identify possible interaction partners. Here, the choice of yeast replication plasmids, as used in this particular study, is crucial as it ensures the possibility of losing the unwanted plasmid from the cell through selection pressure. This is especially important in the development of the method using fluorescence activated cell sorting (FACS) to identify individual promising interaction partners based on fluorescence.

Should this vision be realizable, this approach may provide a valuable tool for gleaning new information on how membrane proteins interact with other proteins in healthy cells and could potentially assist in understanding when cellular interaction pathways dysfunction and lead to diseases.

\section{Methods}

Genes, vectors, and strains. There is no direct involvement of human participants in the study. The CaM gene was kindly provided by Rachel Klevit (University of Washington) and the human AQP0 gene, codon optimized for production in yeast, was purchased from Genscript (Piscataway, NJ). The BiFC pairs, including human AQP0 and CaM, were cloned in the p423GPD and p426GPD vectors and transformed to S. cerevisiae (MYA-1662 $^{\mathrm{ma}}$ his3, ura3-52), as previously described ${ }^{25}$. For this specific study the following constructive constructs were selected for evaluation by flow cytometry screening; YFP $-A Q P 0, Y_{N}-A Q P 0+Y_{N}-A Q P 0$, $\mathrm{YFP}_{\mathrm{N}}-\mathrm{AQP0}+\mathrm{YFP}_{\mathrm{C}}-\mathrm{CaM}, \mathrm{YFP}_{\mathrm{N}}-\mathrm{AQP} 0 \Delta+\mathrm{YFP}_{\mathrm{C}}-\mathrm{CaM}, \mathrm{YFP}_{\mathrm{N}}-\mathrm{AQP0}, \mathrm{YFP}_{\mathrm{N}}-\mathrm{AQP0}$ and $\mathrm{YFP}_{\mathrm{C}}-\mathrm{CaM}$

Chemical transformation of S. cerevisiae. For transformation of plasmids, S. cerevisiae cells with HIS or HIS/URA deficiency selection marker (MYA-1662 $2^{\mathrm{Tm}}$ strain) were inoculated in $5 \mathrm{ml}$ YPD medium and grown overnight at $30^{\circ} \mathrm{C}$ while shaking. The next day, the cells were inoculated in $50 \mathrm{ml}$ YPD medium to a starting $\mathrm{OD}_{600}$ of 0.25 and grown at $30^{\circ} \mathrm{C}$ to reach an $\mathrm{OD}_{600}$ between 0.7 and 1.0. For the chemical transformation, cells were fractionated into $50 \mu \mathrm{l}$ batches and for a single plasmid transformation, each batch was mixed with $240 \mu \mathrm{l}$ freshly prepared PEG4000 (50\%), $36 \mu \mathrm{l} 1 \mathrm{M}$ freshly prepared LiAc, $50 \mu \mathrm{g}$ freshly denatured salmon sperm, 1-2 $\mu \mathrm{g}$ (maximum $10 \mu \mathrm{g}$ ) of plasmid DNA and mQ water was added to a final volume of $360 \mu \mathrm{l}$. In case of double plasmid transformation, a minimum of $2 \mu \mathrm{g}$ (maximum $10 \mu \mathrm{g}$ ) of each plasmid DNA must be used. The mixture was incubated at $30^{\circ} \mathrm{C}$ for $30 \mathrm{~min}$ with shaking and a subsequent heat shock followed for $25 \mathrm{~min}$ at $42^{\circ} \mathrm{C}$. The cells were spun down for $15 \mathrm{~s}$ at $5.500 \mathrm{~g}$. The pellet was resuspended in $200 \mu \mathrm{lmQ}$ water, transformed cells were plated out on selective SC-agar plates and incubated at $30^{\circ} \mathrm{C}$. The single colonies were grown for at least three days, to become fully visible on the SC-agar plates.

Growth of transformants producing the BiFC complexes. Twenty colonies from each transformation were picked and transferred to a fresh SC media agar plate (Masterplate) and grew overnight at $30^{\circ} \mathrm{C}$. For each BiFC construct and control, twelve colonies were regrown overnight in $5 \mathrm{ml} \mathrm{SC}$ medium at $30^{\circ} \mathrm{C}$ with shaking. The criterion for the selection of the twelve colonies chosen was the amount of material provided by each colony to successfully start a preculture. The following day, the cells from the overnight culture were diluted to $\mathrm{OD}_{600}=0.2$ into a 12 -well tissue culture plate and incubated at $30^{\circ} \mathrm{C}$ while shaking to reach an $\mathrm{OD}_{600}$ of 0.5 , assuring a generation time of two hours being a quality marker for a culture of healthy cells. Cultures having a prolonged generation time were not included in the fluorescence analysis.

Fluorescence readout using flow cytometry. Fluorescence intensities of the cell samples were evaluated using a FACSMelody (BD) flow cytometer (100 $\mu \mathrm{m}$ nozzle size, blue excitation laser at $488 \mathrm{~nm})$. For the fluorescence measurements, $500 \mu \mathrm{l}$ sample, cell culture of $\mathrm{OD}_{600}=0.5$, was loaded into the FACS machine assuring a good resuspension of the cells. Debris and non-uniform cells were excluded and the fluorescence intensity of 100.000 cells of the live population was excited at $488 \mathrm{~nm}$ and evaluated on the FITC channel $(527 / 32 \mathrm{~nm}$ bandpass filter). A threshold was set at 500 fluorescent intensity units to distinguish between autofluorescence and YFP signal.

Immunoblot analysis. To confirm equal expression levels of the BiFC constructs, cell lysates were evaluated using Immunoblot analysis. In brief, the cells of an overnight culture of the different constructs were spun down (5.500 g, $5 \mathrm{~min}$.) and diluted in PBS to an $\mathrm{OD}_{600}$ of 5. Each sample was resuspended in $200 \mu \mathrm{l} 1 \times \mathrm{SDS}$

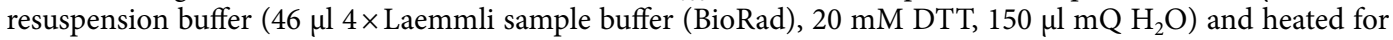
$8 \mathrm{~min}$ at $95^{\circ} \mathrm{C}$. Cell debris were spun down $(15.000 \mathrm{~g}, 5 \mathrm{~min})$ and $14 \mu \mathrm{l}$ of each sample were loaded on a SDS- 
PAGE gel (BioRad Protean TGX, 4-20\%, $16 \mathrm{~min}, 300 \mathrm{~V}$ ). A fast blotting procedure was performed (BioRad Trans-Blot Turbo, TGX Turbo protocol) to a PVDF membrane (Amersham Hybond PVDF). Three different antibodies were used in separate immunoblots directed towards the YFP split YFP variants (anti YFP $_{\mathrm{C}}$ : Roche Diagnostics \#11814460001; anti $\mathrm{YFP}_{\mathrm{N}}$ : BioLegend \#902601), respectively, using a Pierce Fast Western Blot kit (ECL substrate) from Thermo Scientific. The chemiluminescence signal was detected via luminol enhancement from the kit and detection was manually performed and captured using a ChemiDoc MP imager from BioRad and Image Lab software.

Fluorescence microscopy and image analysis. To confirm intracellular production of the BiFC complexes, cells of an overnight cultures of the different constructs were diluted to $\mathrm{OD}_{600}=0.2$ into $50 \mathrm{ml}$ Falcon tubes and incubated at $30^{\circ} \mathrm{C}$ to reach an $\mathrm{OD}_{600}$ of 0.5 . Cells were spun down at $3000 \mathrm{~g}$ for $5 \mathrm{~min}$ and resuspended in $500 \mu \mathrm{H}_{2} \mathrm{O}$. The cell suspension was used to acquire the fluorescence images.

Images of the transformants were generated with an exposure time of $200 \mathrm{~ms}$ at an inverted Zeiss Axio Observer Z1 fluorescence microscope with an Axiocam 506 camera. A Plan-Apochromat 100x/1.40 oil DIC M27 objective was fitted to the microscope. YFP excitation was performed at $508 \mathrm{~nm}$, using a $450-490 \mathrm{~nm}$ filter with a HXP mercury short-arc lamp. The emitted fluorescence light at $524 \mathrm{~nm}$ was analysed after passing a 500-550 nm filter. Zeiss Zen blue software was used to capture and process the data. For each construct, at least five different field of views (FOVs) were evaluated by moving the stage to obtain non-overlapping images, and the FOVs were randomly selected to avoid bias. A comparison with the single plasmid control $\mathrm{YFP}_{\mathrm{C}}-\mathrm{CaM}$ was performed to distinguish signals from the background signal. Broken cells were not included in the data analysis. The imaging was repeated at least twice.

Statistical analysis. Statistic details for the experiments performed can be found in the legend of Fig. 5. An unpaired two component t-test with Welch's correction was used to determine statistical difference between the control groups $(p<0.0001)$.

Received: 6 July 2021; Accepted: 14 September 2021

Published online: 28 September 2021

\section{References}

1. Safari-Alighiarloo, N., Taghizadeh, M., Rezaei-Tavirani, M., Goliaei, B. \& Peyvandi, A. A. Protein-protein interaction networks (PPI) and complex diseases. Gastroenterol. Hepatol. Bed Bench 7, 17-31 (2014).

2. Yin, H. \& Flynn, A. D. Drugging membrane protein interactions. Annu. Rev. Biomed. Eng. 18, 51-76 (2016).

3. Hubbard, J. A., Szu, J. I. \& Binder, D. K. The role of aquaporin-4 in synaptic plasticity, memory and disease. Brain Res. Bull. 136, $118-129$ (2018).

4. Mader, S. \& Brimberg, L. Aquaporin-4 water channel in the brain and its implication for health and disease. Cells 8, 90 (2019).

5. Papadopoulos, M. C. \& Verkman, A. S. Aquaporin water channels in the nervous system. Nat. Rev. Neurosci. 14, 265-277 (2013).

6. Weinshenker, B. G. \& Wingerchuk, D. M. Neuromyelitis spectrum disorders. Mayo Clin. Proc. 92, 663-679 (2017).

7. Meli, R., Pirozzi, C. \& Pelagalli, A. New perspectives on the potential role of aquaporins (AQPs) in the physiology of inflammation. Front. Physiol. 9, 101 (2018).

8. Sisto, M., Ribatti, D. \& Lisi, S. Aquaporin water channels: New perspectives on the potential role in inflammation. Adv. Protein Chem. Struct. Biol. 116, 311-345 (2019).

9. Kitchen, P. et al. Targeting aquaporin-4 subcellular localization to treat central nervous system edema. Cell 181, 784-799e719 (2020).

10. Sylvain, N. J. et al. The effects of trifluoperazine on brain edema, aquaporin-4 expression and metabolic markers during the acute phase of stroke using photothrombotic mouse model. Biochim. Biophys. Acta Biomembr. 1863, 183573 (2021).

11. Miura, K. An overview of current methods to confirm protein-protein interactions. Protein Pept. Lett. 25, 728-733 (2018).

12. Douzi, B. Protein-protein interactions: Surface plasmon resonance. Methods Mol. Biol. 1615, 257-275 (2017).

13. Choi, S. G., Richardson, A., Lambourne, L., Hill, D. E. \& Vidal, M. Protein interactomics by two-hybrid methods. Methods Mol. Biol. 1794, 1-14 (2018).

14. Lin, J. S. \& Lai, E. M. Protein-protein interactions: Co-immunoprecipitation. Methods Mol. Biol. 1615, 211-219 (2017).

15. Louche, A., Salcedo, S. P. \& Bigot, S. Protein-protein interactions: Pull-down assays. Methods Mol Biol 1615, 247-255 (2017)

16. Zhou, M., Li, Q. \& Wang, R. Current experimental methods for characterizing protein-protein interactions. ChemMedChem 11, 738-756 (2016).

17. Wade, M., Mendez, J., Coussens, N. P., Arkin, M. R. \& Glicksman, M. A. Inhibition of protein-protein interactions: Cell-based assays. In Assay guidance manual (eds Markossian, S. et al.) (Eli Lilly \& Company, 2004).

18. Wang, S., Ding, M., Xue, B., Hou, Y. \& Sun, Y. Live cell visualization of multiple protein-protein interactions with BiFC rainbow. ACS Chem. Biol. 13, 1180-1188 (2018).

19. Berendzen, K. W. et al. Screening for in planta protein-protein interactions combining bimolecular fluorescence complementation with flow cytometry. Plant Methods 8, 25 (2012).

20. Riese, F. et al. Visualization and quantification of APP intracellular domain-mediated nuclear signaling by bimolecular fluorescence complementation. PLoS ONE 8, e76094 (2013).

21. Hu, C. D., Chinenov, Y. \& Kerppola, T. K. Visualization of interactions among bZIP and Rel family proteins in living cells using bimolecular fluorescence complementation. Mol. Cell 9, 789-798 (2002).

22. Ozalp, C., Szczesna-Skorupa, E. \& Kemper, B. Bimolecular fluorescence complementation analysis of cytochrome p450 2c2, 2e1, and NADPH-cytochrome p450 reductase molecular interactions in living cells. Drug Metab. Dispos. 33, 1382-1390 (2005).

23. Tao, K., Waletich, J. R., Arredondo, F. \& Tyler, B. M. Manipulating endoplasmic reticulum-plasma membrane tethering in plants through fluorescent protein complementation. Front. Plant Sci. 10, 635 (2019).

24. Kerppola, T. K. Design and implementation of bimolecular fluorescence complementation (BiFC) assays for the visualization of protein interactions in living cells. Nat. Protoc. 1, 1278-1286 (2006)

25. Sjohamn, J., Bath, P., Neutze, R. \& Hedfalk, K. Applying bimolecular fluorescence complementation to screen and purify aquaporin protein:protein complexes. Protein Sci. 25, 2196-2208 (2016). 
26. Kreida, S., Roche, J. V., Olsson, C., Linse, S. \& Tornroth-Horsefield, S. Protein-protein interactions in AQP regulation-Biophysical characterization of AQP0-CaM and AQP2-LIP5 complex formation. Faraday Discuss. 209, 35-54 (2018).

27. Hua, Y. et al. Screening for host proteins interacting with Escherichia coli O157:H7 EspF using bimolecular fluorescence complementation. Future Microbiol. 13, 37-58 (2018).

28. Kim, Y., Jung, J. P., Pack, C. G. \& Huh, W. K. Global analysis of protein homomerization in Saccharomyces cerevisiae. Genome Res. 29, 135-145 (2019).

29. Kojima, T., Karasawa, S., Miyawaki, A., Tsumuraya, T. \& Fujii, I. Novel screening system for protein-protein interactions by bimolecular fluorescence complementation in Saccharomyces cerevisiae. J. Biosci. Bioeng. 111, 397-401 (2011).

30. Murozuka, E., Hanisch, S., Pomorski, T. G., Jahn, T. P. \& Schjoerring, J. K. Bimolecular fluorescence complementation and interaction of various Arabidopsis major intrinsic proteins expressed in yeast. Physiol. Plant. 148, 422-431 (2013).

31. Weber-Boyvat, M. et al. Bimolecular fluorescence complementation (BiFC) technique in yeast Saccharomyces cerevisiae and mammalian cells. Methods Mol. Biol. 1270, 277-288 (2015).

32. Hernandez-Sanchez, I. E. et al. Evidence for in vivo interactions between dehydrins and the aquaporin AtPIP2B. Biochem. Biophys. Res. Commun. 510, 545-550 (2019).

33. Xin, S. et al. Expression of tomato SITIP2;2 enhances the tolerance to salt stress in the transgenic Arabidopsis and interacts with target proteins. J. Plant Res. 127, 695-708 (2014).

34. Dirk, B. S. et al. Viral bimolecular fluorescence complementation: A novel tool to study intracellular vesicular trafficking pathways. PLOS ONE 10, e0125619 (2015).

35. Kodama, Y. \& Hu, C. D. Bimolecular fluorescence complementation (BiFC): A 5-year update and future perspectives. Biotechniques 53, 285-298 (2012).

36. Norris, J. L. \& Hughes, R. M. protaTETHER - a method for the incorporation of variable linkers in protein fusions reveals impacts of linker flexibility in a PKAc-GFP fusion protein. FEBS Open Bio 8, 1029-1042 (2018).

37. Wurz, A. I., O'Bryant, C. T. \& Hughes, R. M. protaTETHER: A method for the incorporation of linkers in biomacromolecules. Methods Enzymol. 647, 83-106 (2021).

38. Horstman, A., Tonaco, I. A., Boutilier, K. \& Immink, R. G. A cautionary note on the use of split-YFP/BiFC in plant protein-protein interaction studies. Int. J. Mol. Sci. 15, 9628-9643 (2014).

39. Miller, K. E., Kim, Y., Huh, W. K. \& Park, H. O. Bimolecular Fluorescence Complementation (BiFC) analysis: Advances and recent applications for genome-wide interaction studies. J. Mol. Biol. 427, 2039-2055 (2015).

\section{Acknowledgements}

The work presented in this study was supported by research grants from the Swedish research Council (K201366X-20431-07-05) to Richard Neutze and the Brain Foundation (FO2018-0231) to Kristina Hedfalk as well as financial support from the Department of Chemistry and Molecular Biology, Gothenburg University. We also acknowledge Ulf Yrlid, Samuel Alsén and Rebecca Andersson; Department of Microbiology and Immunology, Gothenburg University, for their kind assistance in the analysis of the flow cytometry data and Peter Dahl for providing the yeast strain.

\section{Author contributions}

R.N. and K.H. conceived the study and devised the experimental strategy with F.S. and J.G. F.S. and J.G. performed experiments and analyzed data together with R.N. and K.H. F.S. and J.G. wrote the draft of the manuscript. All authors revised and approved the final version of the manuscript.

\section{Funding}

Open access funding provided by University of Gothenburg.

\section{Competing interests}

The authors declare no competing interests.

\section{Additional information}

Supplementary Information The online version contains supplementary material available at https://doi.org/ 10.1038/s41598-021-98810-2.

Correspondence and requests for materials should be addressed to K.H.

Reprints and permissions information is available at www.nature.com/reprints.

Publisher's note Springer Nature remains neutral with regard to jurisdictional claims in published maps and institutional affiliations.

(c) (i) Open Access This article is licensed under a Creative Commons Attribution 4.0 International License, which permits use, sharing, adaptation, distribution and reproduction in any medium or format, as long as you give appropriate credit to the original author(s) and the source, provide a link to the Creative Commons licence, and indicate if changes were made. The images or other third party material in this article are included in the article's Creative Commons licence, unless indicated otherwise in a credit line to the material. If material is not included in the article's Creative Commons licence and your intended use is not permitted by statutory regulation or exceeds the permitted use, you will need to obtain permission directly from the copyright holder. To view a copy of this licence, visit http://creativecommons.org/licenses/by/4.0/.

(C) The Author(s) 2021 